\title{
Re (Cell) LCD: A Feasibility Study On Recycling Cell Phone LCDS
}

\author{
Abdulaziz Alotaibi, Christopher Beaschler, Siddharth Rathod, Matt Shea
}

\begin{abstract}
Liquid Crystal Displays (LCD) are used in a magnitude of devices and have now become the norm in products that require a screen, such as, cell phones, computers, televisions, tablets, and more. However, many of these technologies are becoming outdated leading towards the issue of exponential growth of waste with a lack of technology set in place for proper recycling. Most of research literatures on LCD recycling are of electronic products and e-waste in general rather than cell phones in particular. Few studies on recycling of cell phone LCD have been accomplished. Since everyday around 300,000 mobile phones are sent to trash in United States alone, the recycling of LCD of cell phones is still a challenge for recyclers. In this paper four main topics will be discussed: Establishing need of recycling of LCD due to its environmental impacts, increasing number of LCD usage with time, current EoL (End of Life) process and challenges associated with it in terms of environment, economy and social aspects. By our findings, we are aiming to examine the sustainable feasibility of recycling LCD of cell phones comparing with other LCD products. Our approach for obtaining data for LCD of cell phones is to simulate details from other LCD products (LCD Monitor, LCD PC, LCD TV) such as main elements, recovery of substances, energy required to produce, etc.Finally, we will conclude with the observations with important considerations for a holistic approach to make LCD recycling of cell phones feasible. The results aim to enable recyclers to add confidence in LCD recycling of cell phones and also for researchers to extend this work with innovative ways and cost-effective approach in future.
\end{abstract}

Keywords: End of Life (EOL), Liquid Crystal Displays (LCD), Recycling, Feasibility, Environmental Impact, Economic Assessment

\section{INTRODUCTION}

Liquid Crystal Displays (LCD) are used in a magnitude of devices and have now become the norm in products that require a screen, such as, cell phones, computers, televisions, tablets, and more. However, many of these technologies are becoming outdated leading towards the issue of exponential growth of waste with a lack of technology set in place for proper recycling. In this paper four main topics will be discussed: Establishing need of recycling of LCD due to its environmental impacts, increasing number of LCD usage with time, current EoL (End of Life) process and challenges associated with it in terms of environment, economy and social aspects. By our findings, we are aiming to examine the technical feasibility of recycling LCD of cell phones comparing with other LCD products.

New technologies have become a way of the future, often going along with the quote, out with the old and in with the new. However, what happens to the old LCD's when found to be "useless" can actually propose some serious problems to our health. The smartphone is a prime example of this issue seen today. It can be seen in the hands of all types of people from the elderly to small toddlers, and is always improving. However, with the hundreds of different phones in the world, what is being done with the obsolete phones today? The answer is very little. According to a study done by Purdue University [8] "Over the next few years, it is expected that hundreds of millions of cold cathode fluorescent lamps or CCFL-backlit LCDs will retire each year" and with this increased growth in obsolete phones comes serious problems.

With the amount of increased technologies becoming obsolete the lack of technology for recycling purposes have led to numerous issues. The main concern is environmental issues, "More than 3 million tons of e-waste were generated in 2007 in the United States, with 13.6 percent collected for recycling and 86.4 percent going to landfills and incinerators" [8]. This $86.4 \%$ going to the landfills and incinerators is only releasing "hazardous chemicals such as heavy metals and brominated flame retardants," this will then seep into the soils and water sources. Besides, the environmental issues of the exponential waste there lies another component, this being the amount of parts that can be recycled from each unusable LCD application. Silveira [9] mentions that the "recycling cell phone components can be as high as $80 \%$," leading to an enormous percentage that can be kept from piling up in the landfill and recycled into new and more efficient technologies. Therefore, the importance of investing in evolutionary technologies to improve recycling LCD's is progressing at the speed of the exponential e-waste being sent to the landfills today.The environmental impacts of LCDs disposal are 
significant and increasing, according to [1] liquid crystal displays are widely used in the last few years due to mass production and the variety of products that use LCDs and the advantages LCD technology has over conventional displays. However, the life span for LCDs is about 10 years and new LCD displays that outdate their older predecessors will be in the market in the near future. Therefore, a huge number of LCDs will face an end-of-life process. In [3] the authors presented the issue of end-of-life process of LCDs and the amount of the number of sales of LCDs in comparison to other products like CRT, OLED. Millions of tonnes of e-waste in the United States are being discarded into landfills, about $1.36-1.72$ million metric tonnes, of which 0.34 million went to recycling [2]. Europe is the region considered to be leading in LCD recycling [2]. [4] Brought up the challenges in recycling LCDs, and how LCDs is a relatively new technology, with recycling methods yet to be invented. In addition, this article presented the differences between LCD products such as LCD in laptops, monitors, and TVs. Also, it estimates the amount of mass for each of these products that will undergo end-of-life process. [5] Investigated the amount of LCDs that has been discarded to landfills or incinerated. $15 \%$ of the waste goes to recycling where 55\% is sent to landfills in forms of solid waste and hazardous waste, another 15\% is being remanufactured and the remaining $15 \%$ undergoes incineration process. Due to the lack of information on this subject, assumptions were made to arrive at these percentages and sensitivity analyses took place in this study to validate these assumptions [5].

This paper will discuss the current end of life process that LCDs go through, while establishing the importance of why it is necessary to change the process of current recycling methods. Research explains that an isopropyl alcohol solution can dissolve liquid crystals from the glass product and an incredible 100 percent of the weight is able to be recovered [6]. As Zhuang et al. discuss further, the polarizer is also largely separated from the glass and is able to be recovered as well [6]. This and other methods need to be explored and utilized as quickly as possible. The LCD development and practical use of the product accord faster than proper research could be advanced to determine ways to reuse or recycle the technology. However, it is a very useful technology, Tyagi and Chatterjee describe LCDs as a help to all the new smaller technologies that require a lower power consumption, while also having less space to deal with [7]. Not only has the recycling process not been explored enough, but the impact of this helpful technology is not explored far enough in advance for it to be considered a true help for the environment [7]. Currently, when the LCD product reaches the end of its life the majority of the LCD is being either incarcerated or thrown into landfills [3]. As Ryan et al., points out this leaves a large amount of materials left to waste; these materials include metals such as steel, aluminum, and copper [3]. Leaving these types of products unused in landfills is unacceptable. Few studies on recycling of cell phone LCD have been accomplished. Most of research literatures on LCD recycling are of electronic products and e-waste in general rather than cell phones in particular [9]. Since everyday around 300,000 mobile phones are sent to trash in United States alone [10], the recycling of LCD of cell phones is still a challenge for recyclers. Our approach for obtaining data for LCD of cell phones is to simulate details from other LCD products (LCD Monitor, LCD PC, LCD TV) such as main elements, recovery of substances, energy required to produce, etc. The next step is to provide possible suggestions to lower down the cost of current EoL process and efficient ways to recover maximum material. Finally, we conclude with the observations with important considerations for a holistic approach to make LCD recycling of cell phones feasible. The results aim to enable recyclers to add confidence in LCD recycling of cell phones and also for researchers to extend this work with innovative ways and cost-effective approach in future.

\section{METHODOLOGY}

In the current LCD recycling process there are many components to consider. Currently, the different devices that use LCD's is important to establish an understanding into the LCD recycling, however, the main area of concern is the universal categories that the user can use when aiming to recycle LCD's. In most LCD products these categories consist of the front frame, the LCD panel, plastic housing, film set, back frame, backlight assembly, power supply and controller, a rear cover, and a base/stand [6]. Currently the United States is "generating more than 3 million tons of e-waste (per year), with $13.6 \%$ collected for recycling and $86.4 \%$ going to landfills and incinerators" [16]. However, due to the environmental concerns of the waste that LCD's produce there has been an increase in state regulations for e-waste [16]. With these regulations there is a push to decrease the landfill growth of e-waste exponentially. This has led to a recycling process as seen in Figure 1 below. 


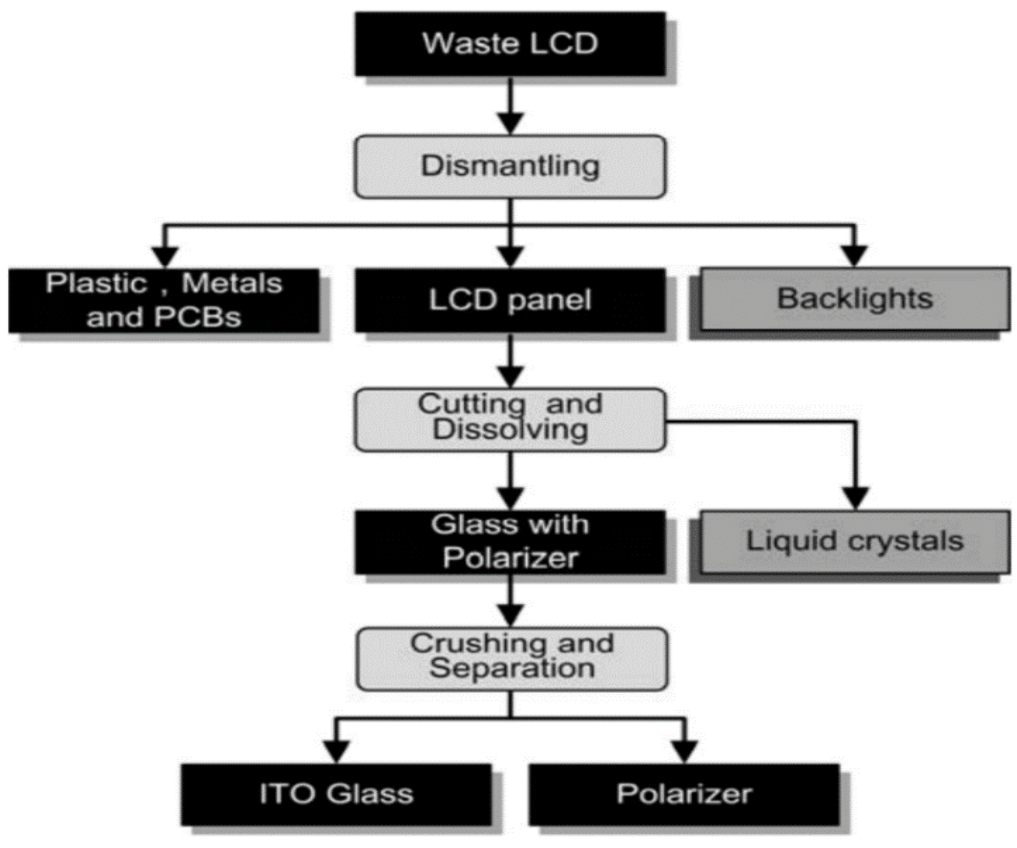

Figure 1, LCD Recycling Diagram [16]

This push has led to the implementation of new ways and processes to extract material from current LCD devices. For example, the two main processes for LCD recycling include the removal of the liquid crystals and recovery of glass and polarizer [6]. These processes can be achieved in two different ways. First, the removal of the liquid crystals can be removed with a chemical solution. In fact, a study showed that by using isopropyl alcohol solution and ultrasound nearly all of the liquid crystals can be removed, on a weight percent basis [6]. This was done, unfortunately, with a high time demand and at a high temperature. This high time demand reduces the profitability, while the high temperature requires more energy to be used during the process, generating negative environmental effects. As for the second process, the recovery of glass and polarizer, the study used a crushing strategy along with gravity to isolate the two products [6]. These results were not as efficient but very promising, "up to $79.7 \mathrm{wt} \%$ of polarizer was separated from glass" [6]. These two processes show that a high yield can be achieved in LCD recycling. However, the concerns of the current process today have raised apprehensions as to fully implementing a sustainable recycling process.

Not only have there been economical concerns, as stated above, but there have also been safety concerns as well. As shown in Table 1, there are many health concerns that come from not properly disposing of LCD's rather than looking to recycle. These toxins have posed a potential problem for implementing a fully sustainable process.

Table 1. Material Components to LCD Recycling [6]

\begin{tabular}{|c|c|c|}
\hline Materials and components & Description & Biological toxicity \\
\hline Liquid crystals & $\begin{array}{c}\text { Liquid crystal mixture containing ben- } \\
\text { zene, cyano-group, F, Cl, Br, etc. }\end{array}$ & Potentially harmful to the environment and human health \\
\hline Backlight assembly & Mercury is used & $\begin{array}{r}\text { Harmful to kidneys, liver, nervous system, and the hematologi- } \\
\text { cal system; carcinogenic }\end{array}$ \\
\hline Plastic housing and frames & $\begin{array}{c}\text { Brominated flame retardants such as } \\
\text { PBDE and PBB }\end{array}$ & $\begin{array}{c}\text { Harmful to the brain, kidneys, liver, nervous system, endocrine, } \\
\text { and reproductive system; carcinogenic }\end{array}$ \\
\hline Power supply and controller & $\begin{array}{c}\text { Arsenic (As) and heavy metals such as } \\
\text { lead, cadmium, and chromium }\end{array}$ & $\begin{array}{c}\text { Harmful to the liver, kidneys, skeleton, nervous system, and } \\
\text { hematological system }\end{array}$ \\
\hline
\end{tabular}

The overall technology of LCD recycling is fairly new. However, it is looking to vastly expand for future growth due to the extremely high rates of e-waste generated every year. LCD recycling will not only help prevent harmful toxins from polluting the environment, but will also 
reduce the extraction of precious metals. With further testing and implementation of new technology the field of LCD recycling must continue to grow in order to keep up with the ever increasing waste.

After conducting many literature research, we came up with a conclusion that LCD recyclers were more focused on recycling LCD parts from laptops, TVs, and monitors. Almost, a very few research were conducted on recycling LCD of cellphones, which raises many questions about its sustainable feasibility. Therefore, the challenge here is to validate the importance of recycling LCD of cellphones considering lack of information. We aim to provide some insights on this matter by comparing actual processes from other LCD products.

\subsection{Need of Recycling of LCD of cellphone}

LCD screens accompany our daily lives. Most major electronic equipment is shipped with a display to facilitate an easy interaction with the user and LCD technology has become the medium of choice because of the advanced technology LCDs present. The cell phone market is increasing in the past 15 years, as figure 2 shows [15]. Worldwide, cell phone subscribers are growth at average $13.5 \%$ per year from 2,205 million to 7,085 million in 2005 to 2015 respectively. Global cell phone subscriptions per 100 inhabitants went from 33.9 in 2005 to 96.8 in 2015.

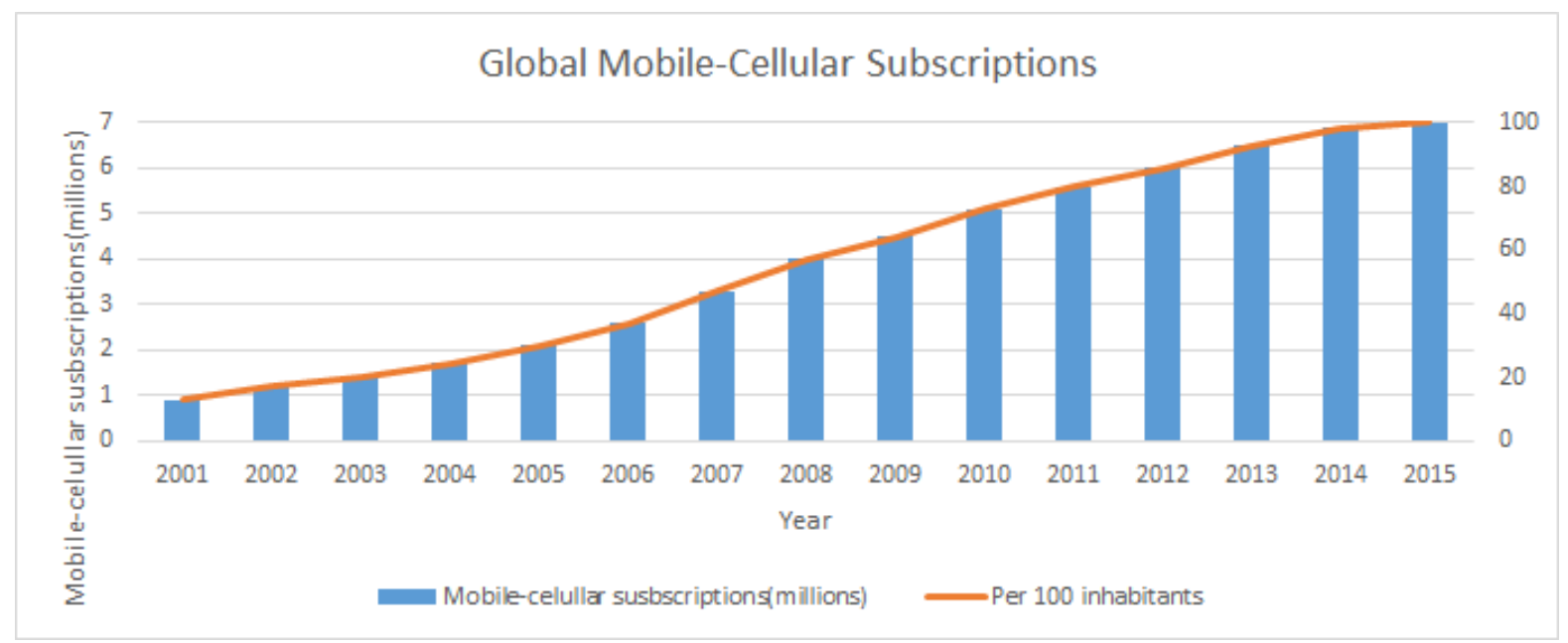

Figure 2. Global mobile-cellular subscriptions [15]

The statistic in figure 3 shows a forecast of the number of mobile users worldwide from 2015 to
2020 , where the global number of mobile users is projected to amount to 9,038 million in 2020 .

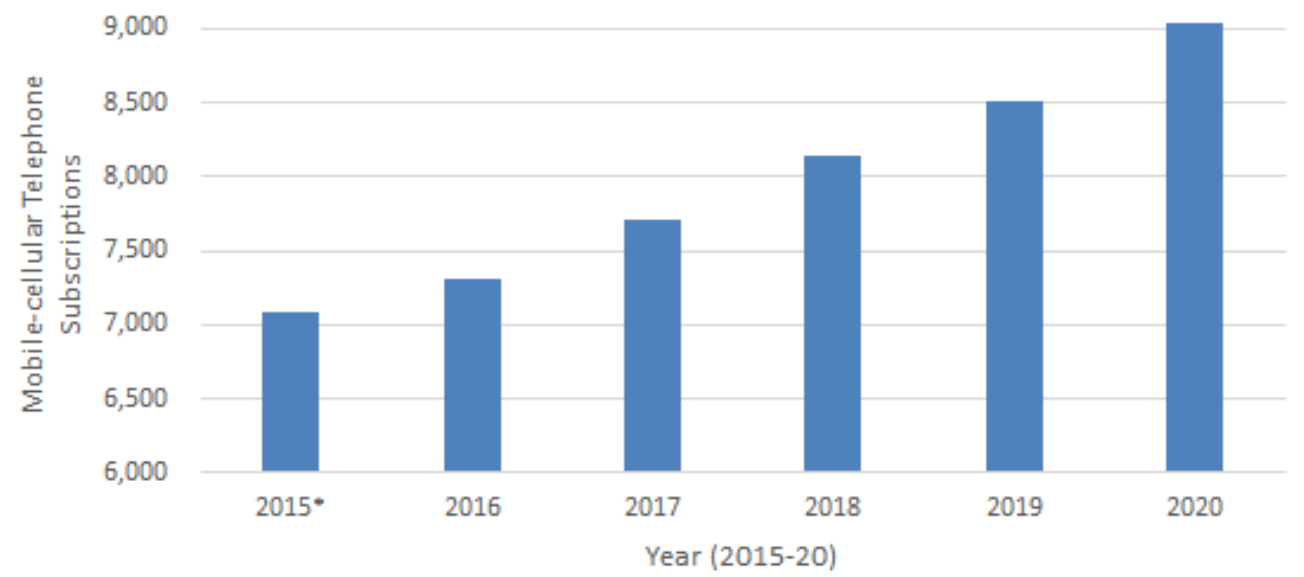

Figure 3. Number of mobile users worldwide between 2010 and 2020 (in millions) (Statistic)

The consumer equipment many LCD screens are built for generally face a short usephase with ever decreasing lifespans. Mobile phone with their average use phase of under 2 years serve as a good example for this phenomenon [15]. In the vast majority, these phones are still perfectly usable 
after their first usage phase, as their mechanical lifetime on average is projected to be 10 years [14]. Due to this reason, a number of recycling programs have been initiated, aiming at collecting and retrieving used phones with the goal of supplying a second-hand market for used devices. However, due to limited awareness and high logistic complexity, these programs manage to collect only about $10 \%$ of used phones in the market [11]. Of the collected phones, $65 \%$ can be reuse with only minor refurbishment, while $35 \%$ are damaged beyond repair and are thus recycled for raw materials [14]. In order to give an overview over the potential waste produced by discarded mobile phones, and comparing the potential for recycling with actual recycling rates of mobile phones, this paper is projecting (future waste).

\subsection{Environmental impact assessment}

From the literature research that we have done, there is not much data about the average compositions of cell phone LCD screens, it is assumed that the technology and thus the material composition is in similar ratio to those of larger screens. This assumption however would need to be verified as it is reasonable to assume that the ratio of casing to actual LCD material is likely to vary. However, as the size and the material composition also varies between manufacturers of cell phones, the model created in this paper aims to be an average representation of cell phone LCDs rather than a model of a specific screen.

From the range of options to process liquid crystal displays at the end of their life, which are: reuse, remanufacture, recycling, burning in order to get energy, storage, the most desirable with healthy effects on the environment is recycling by recovering. There are more stages to disassemble LCD panels is shown in figure 4.

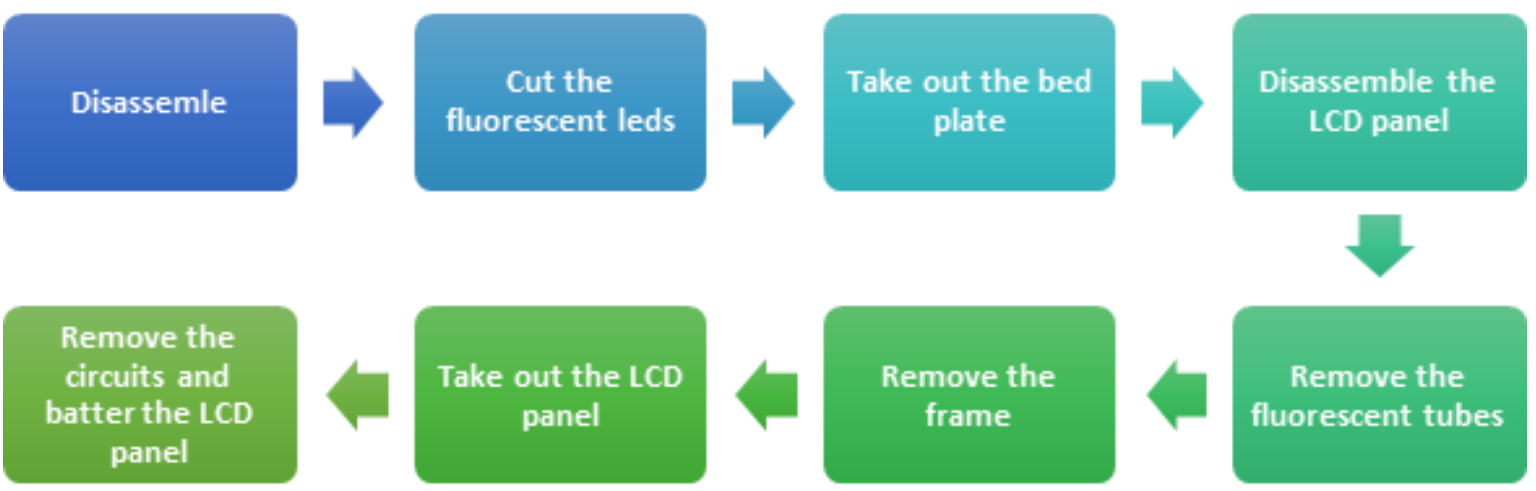

Figure 4. LCD Panels disassembling stages [13]

The material composition of the model created in this paper is based upon data from [3], which is shown in the figure 5 below.

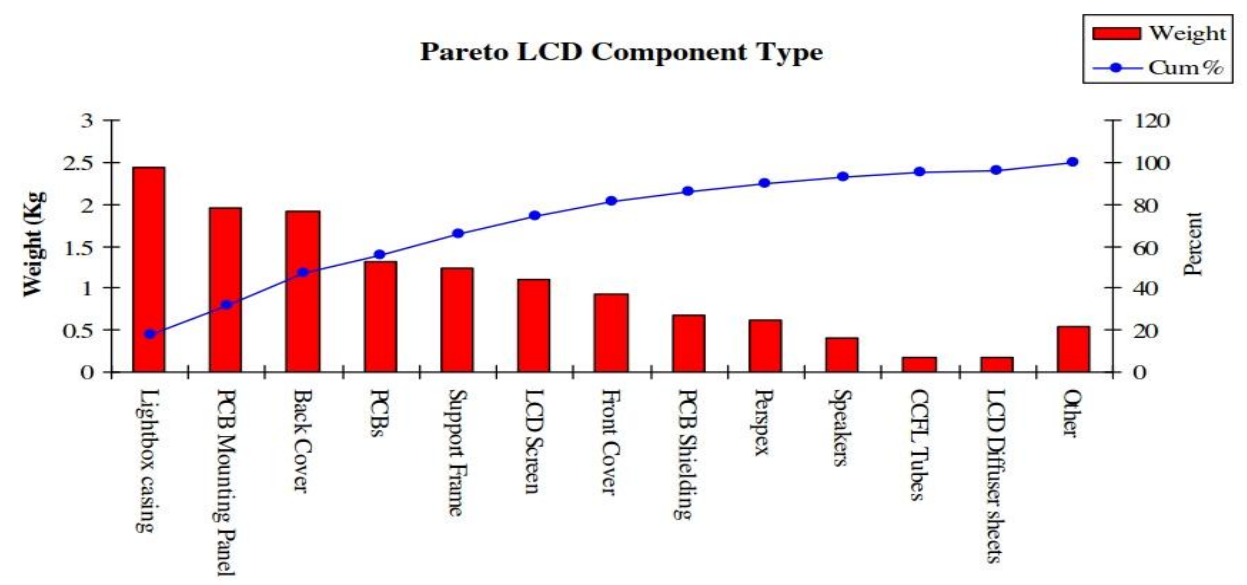

Figure 5. Pareto LCD Component Type [14] 
The chart shows, that plastic material as well as metals from the printed circuit boards together with the liquid crystal glass form the vast majority of material by weight. This assumption is confirmed by [12], showing figure 6 the average raw material composition of LCD displays.

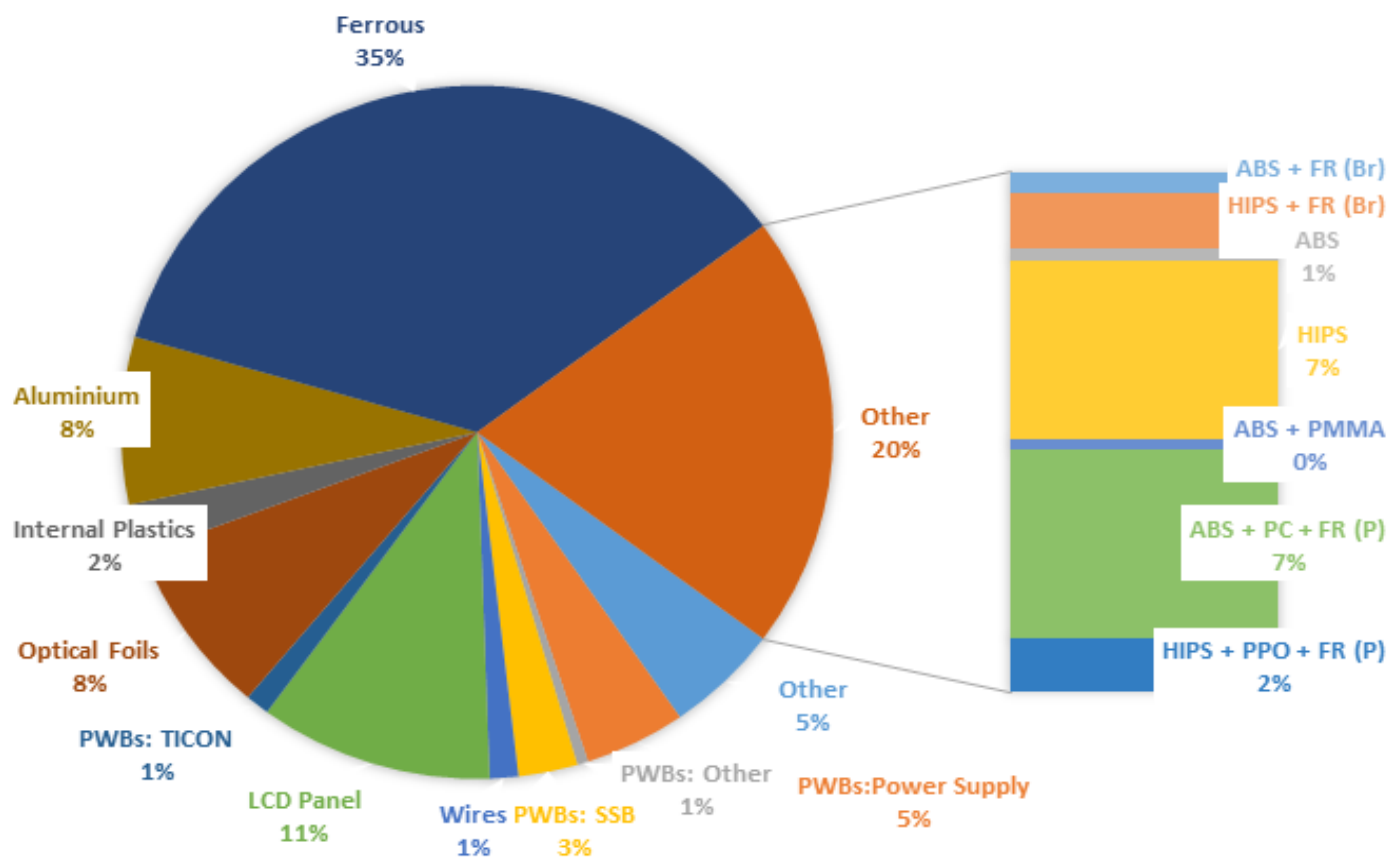

Figure 6. Average Material content in LCD [12]

From knowing the average material content in LCD in other products, we are expecting which compositions are available in LCD of cellphone. Thus, we found the available compounds in LCD of cell phone in table 2. By using this result, we will match with average material content in LCD and find the approximate values of all compounds in LCD of cellphone.

Table 2. Component-level metals content in Cell Phone [17]

\begin{tabular}{|c|c|c|c|c|c|c|c|c|c|c|c|c|c|c|c|c|c|c|c|c|c|c|c|c|}
\hline Metal & $\mathrm{Au}^{+}$ & $\mathrm{Ag}^{+}$ & As & $\mathrm{Ba}$ & $\mathrm{Bi}$ & $\mathrm{Ca}$ & $\mathrm{Cr}$ & $\mathrm{Cu}^{+}$ & Ga & In & $\mathrm{Mn}$ & $\mathbf{N i}$ & $\mathrm{Pb}$ & Pt & Si & Sb & Sn & $\mathrm{Ta}$ & $\mathrm{Ti}$ & $\mathrm{Zn}$ & $\mathrm{Zr}$ & $\mathbf{A l}^{+}$ & $\mathrm{Fe}^{t}$ & $\mathbf{P d}^{+}$ \\
\hline PWB & $\bullet$ & $\bullet$ & $\bullet$ & $\bullet$ & $\bullet$ & & $\bullet$ & $\bullet$ & $\bullet$ & & $\bullet$ & $\bullet$ & $\bullet$ & $\bullet$ & $\bullet$ & & • & • & $\bullet$ & • & • & & & \\
\hline Flex & • & • & & & & & & • & & & & & & • & & & & & & & & & & \\
\hline LCD & $\bullet$ & $\bullet$ & $\bullet$ & $\bullet$ & & $\bullet$ & & $\bullet$ & & $\bullet$ & & $\bullet$ & & & $\bullet$ & $\bullet$ & $\bullet$ & & & & & & & \\
\hline Camera & • & & & & & & & • & & & & • & & & & & & & & & & & & \\
\hline $\begin{array}{l}\text { Audio } \\
\text { components }\end{array}$ & & & & & & & & $\bullet$ & & & $\bullet$ & & & & & & & & & $\bullet$ & & & & \\
\hline
\end{tabular}

Based upon these data, the average composition of the most important parts of LCD screens by weight is concluded, which will be used to model cell phone LCD screens in the LCA software sustainable minds. The software allows for an evaluation of impacts caused by landfilling the material described above.

\subsection{Economic analysis}

An important feature of LCD technology is that it comes in all sizes and forms in order to satisfy a distinguished customer demand to satisfy their expectations. From a recycling perspective, this fact can be considered as major disadvantage as equipment cannot be standardized to facilitate a high and cost-effective throughput of the same material. Furthermore, the typical LCD screen consists of a number of different materials that have to be taken apart and recycled in different processes towards useful end products. In [3], LCD screens of a number of larger displays on the market were taken apart and inspected in order to detect common characteristics on materials and composition of the screens, which is shown in the figure 7 . 


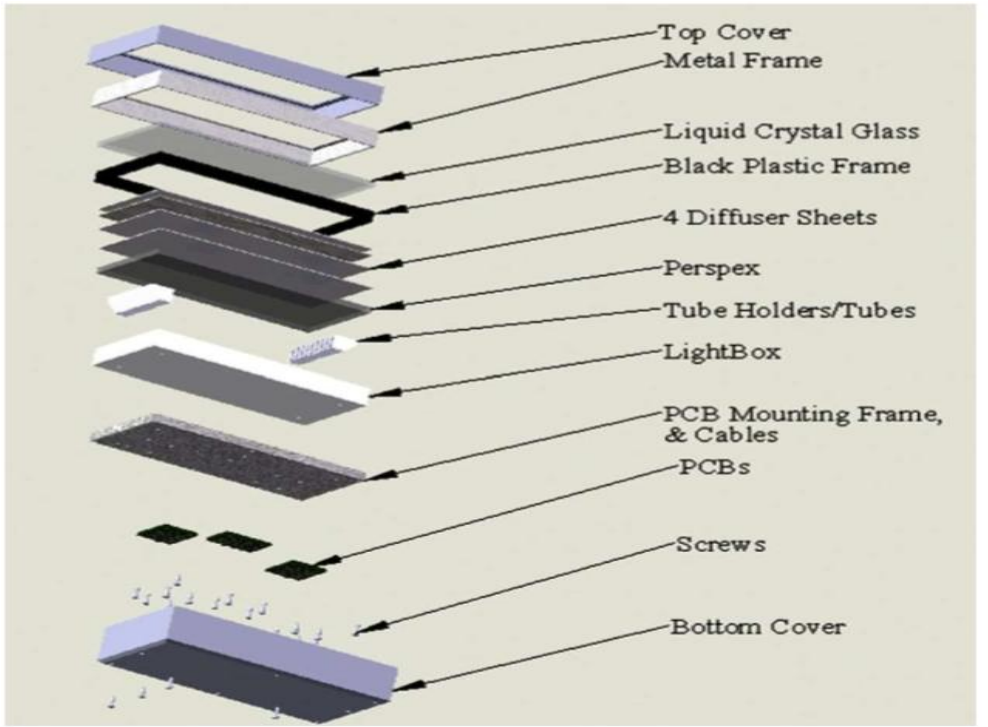

Figure 7. LCD unit exploded view [3]

As can be seen from this figure, an LCD screen is a highly complex device consisting of many different layers of materials that would have to be taken apart in order to realize efficient recycling rates. Taking such an LCD screen apart can take untrained personnel approximately 14 minutes per screen [3]. While this might still be economically feasible for bigger screens (the data suggests LCD recycling rates of around $33 \%$ for larger monitors [18], this aspect is especially challenging in mobile phone LCD screens, as their small size in comparison with other electronic equipment makes the separation of material in an economically feasible way especially difficult. In order to assess the environmental impact of cell phone LCD displays, it is helpful to look closely at the individual parts this technology usually consists of.

The waste streams are as follows:

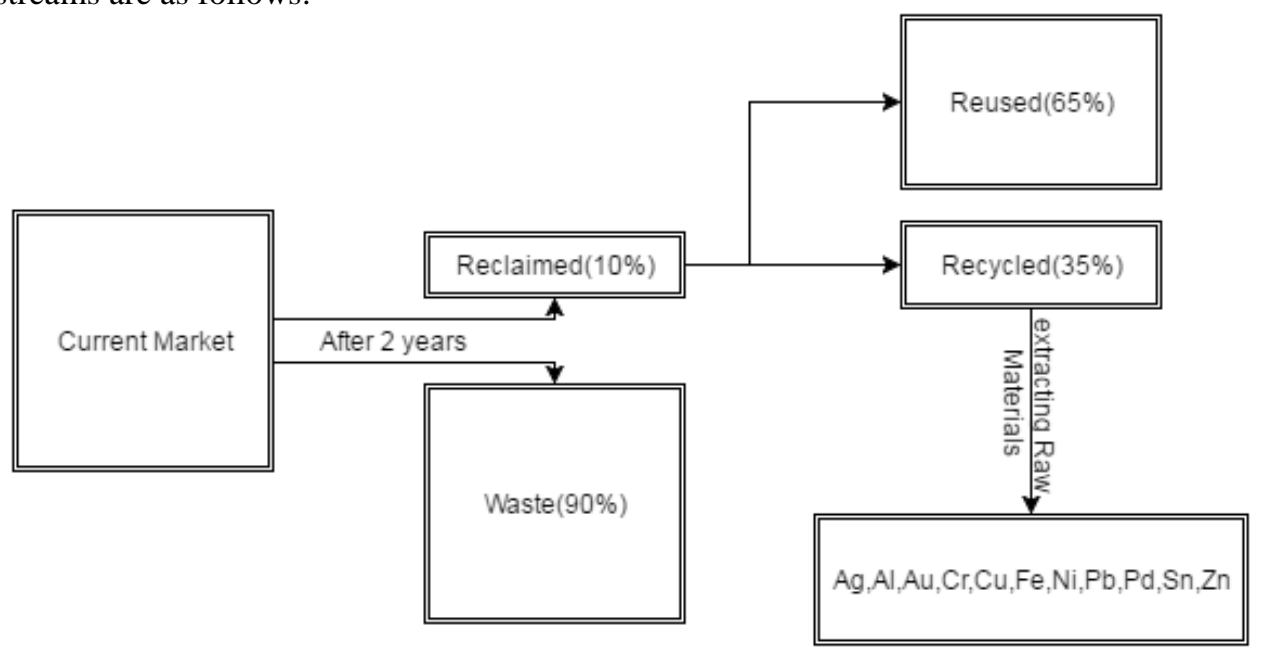

Figure 8. The LCA of cell phone

Figure 8 shows that the biggest impact of cell phone LCD screens is caused by landfilling, and although optimizing the recycling process is important, the most achievement could be made by tackling the direct waste stream and adding cell phones to recycling processes from the beginning. This could be done in two ways. Firstly, it is important to raise social awareness for cell phone recycling in general, and maybe to aid that with legislation. The current recycling movements and laws have been investigated in [14].

This paper tries to look at the alternative: Secondly, it is important to manufacture small LCD screens to make it easier to recycle them in large scales to create economic incentive to reclaim small LCD screens from waste. On the other hand, it is important to design small screens with having in mind that the most part will end on landfills. 
Therefore, it will be feasible to design the screens using degradable materials that have lower environmental impact, and are well-suited for landfills.

Therefore, it is assumed that currently no recycler is interested in small LCD screens and every screen is landfilled. The data above helps in determining the environmental impact if all cell phone LCD screens are landfilled. Based upon this reference scenario, for the most important parts by weight, suggestions are made to either decrease environmental impact by changing the material, or to change the way the screen is built in order to make recycling of small LCD screens easier in large scales. The idea behind that is to increase the economic feasibility of small screen recycling, so there is economic incentive to reclaim cell phone LCDs from the waste stream and add them to a recycling process.

\section{RESULTS}

\subsection{Environmental Feasibility}

There is very little published data on the material composition of LCD screens. Composition of LCD Monitor, TV and cellphones is shown in Table 3.

Table 3. Composition of LCD Monitor, LCD TV and LCD of Cellphone [24]

\begin{tabular}{|c|c|c|c|c|}
\hline Type & Description & $\begin{array}{c}\text { LCD Monitor } \\
(\boldsymbol{\%})\end{array}$ & $\begin{array}{c}\text { LCD TV } \\
(\boldsymbol{\%})\end{array}$ & LCD Cellphone (\%) \\
\hline Metals & & $53.82 \%$ & $59.88 \%$ & $52.33 \%$ \\
\hline & Ferrous & $31.32 \%$ & $44.15 \%$ & $33.50 \%$ \\
\hline & Non-Ferrous & $19.09 \%$ & $2.27 \%$ & $15.20 \%$ \\
\hline & ABS & $14.78 \%$ & $0.00 \%$ & $5.45 \%$ \\
\hline & ABS + PC & $0.00 \%$ & $0.00 \%$ & $0.00 \%$ \\
\hline & PC & $2.09 \%$ & $9.07 \%$ & $7.50 \%$ \\
\hline Other Plastics & PMMA & $17.04 \%$ & $7.85 \%$ & $10.25 \%$ \\
\hline PWBs & POM & $0.00 \%$ & $0.00 \%$ & $0.00 \%$ \\
\hline Wires & & $22.70 \%$ & $25.23 \%$ & $21.37 \%$ \\
\hline LC Assembly & & $6.44 \%$ & $6.06 \%$ & $5.89 \%$ \\
\hline CCFL & & $4.01 \%$ & $0.36 \%$ & $3.35 \%$ \\
\hline
\end{tabular}

A general composition of 20 LCD screens in cellphones is shown in Table 4, but no further information is given about the size or technology of this LCD screen. The LCD screens were composed of different materials, including connectors, adhesives, diffusive sheets, reflective sheets, polarizing film, plastic frame, and LCD panel. The
LCD panels, which on average accounted for $48.89 \%$ of the total mass of the LCD screens, consisted of ITO, liquid crystal, and the two glass plates enclosing these materials. Liquid crystal was not quantified in this study, because it dissolves in acetone, which was used in the process to remove the polymeric film.

Table 4: Characterization of 20 cell phone LCD screens. [9].

\begin{tabular}{|l|l|l|}
\hline Components & Mass $\mathbf{( g )}$ & Percentage (\%) \\
\hline LCD Panel & 58.90 & 48.89 \\
\hline Plastic Frame & 32.93 & 27.34 \\
\hline Polarizing Film & 12.10 & 10.04 \\
\hline Connector & 6.46 & 5.36 \\
\hline Diffusive Sheets & 5.16 & 4.28 \\
\hline Reflective Sheets & 2.75 & 2.28 \\
\hline Adhesives & 2.16 & 1.79 \\
\hline Total & 120.46 & 100 \\
\hline
\end{tabular}




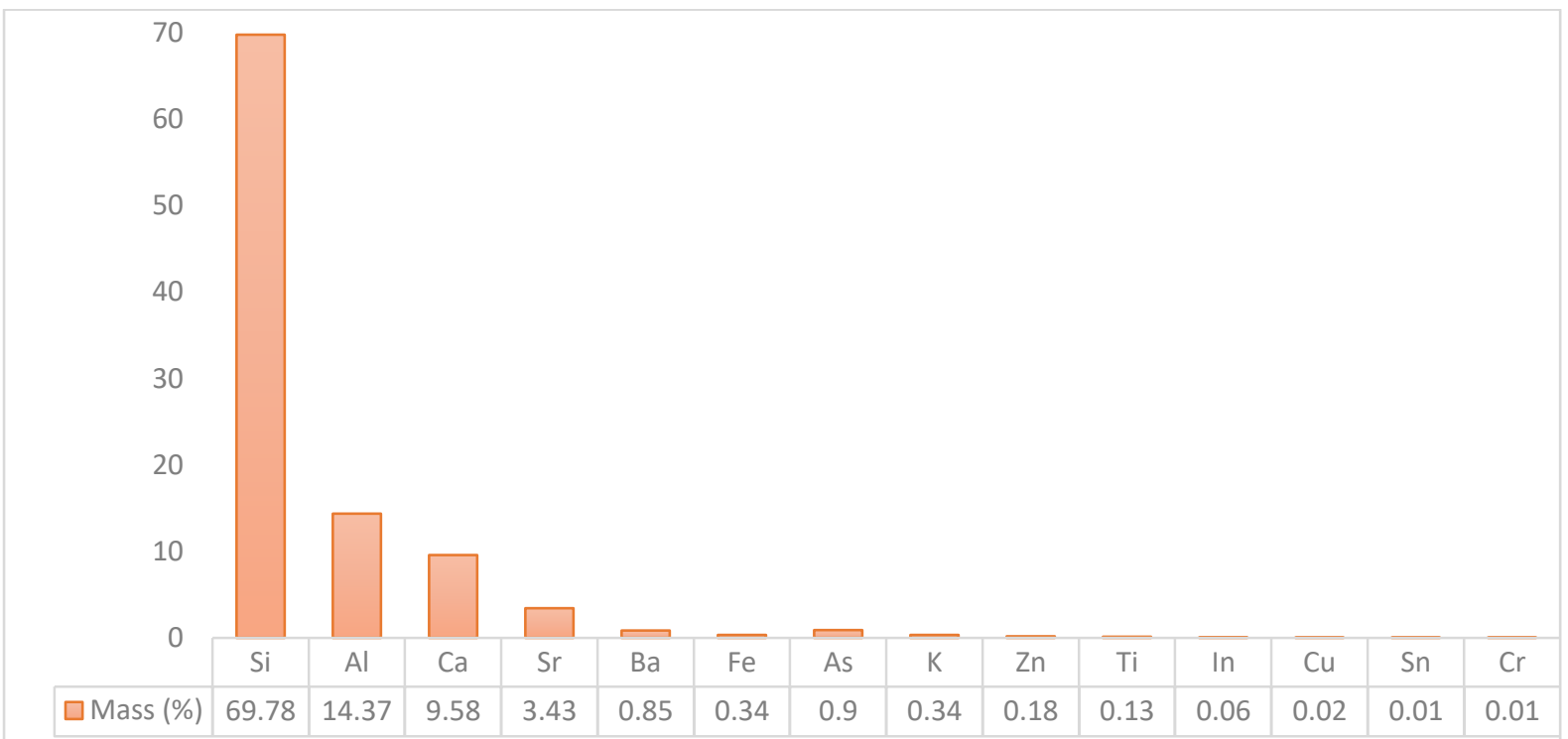

Figure 9. Percentage of main elements of waste LCD after normalization (wt\%) by XRF [21].

For the impact assessment, sustainable mind software was used. The categories are climate change, ecosystem quality, human health and resources, methodology are Acidification Potential (AP), Climate Change (CC),Eutrophication Potential (EP), Freshwater Aquatic Eco-Toxicity Potential (FAETP), Freshwater Sediment EcoToxicity Potential (FSETP), Human Toxicity
Potential (HTP), Ionizing Radiation (IR), Malodours air, Marine Aquatic Eco-Toxicity Potential (MAETP), Marine Sediment EcoToxicity Potential (MSETP), Photochemical ox (summer smog),Abiotic Depletion Potential (ADP), Ozone Depletion Potential(ODP), and Terrestrial Eco-toxicity potential (TETP).

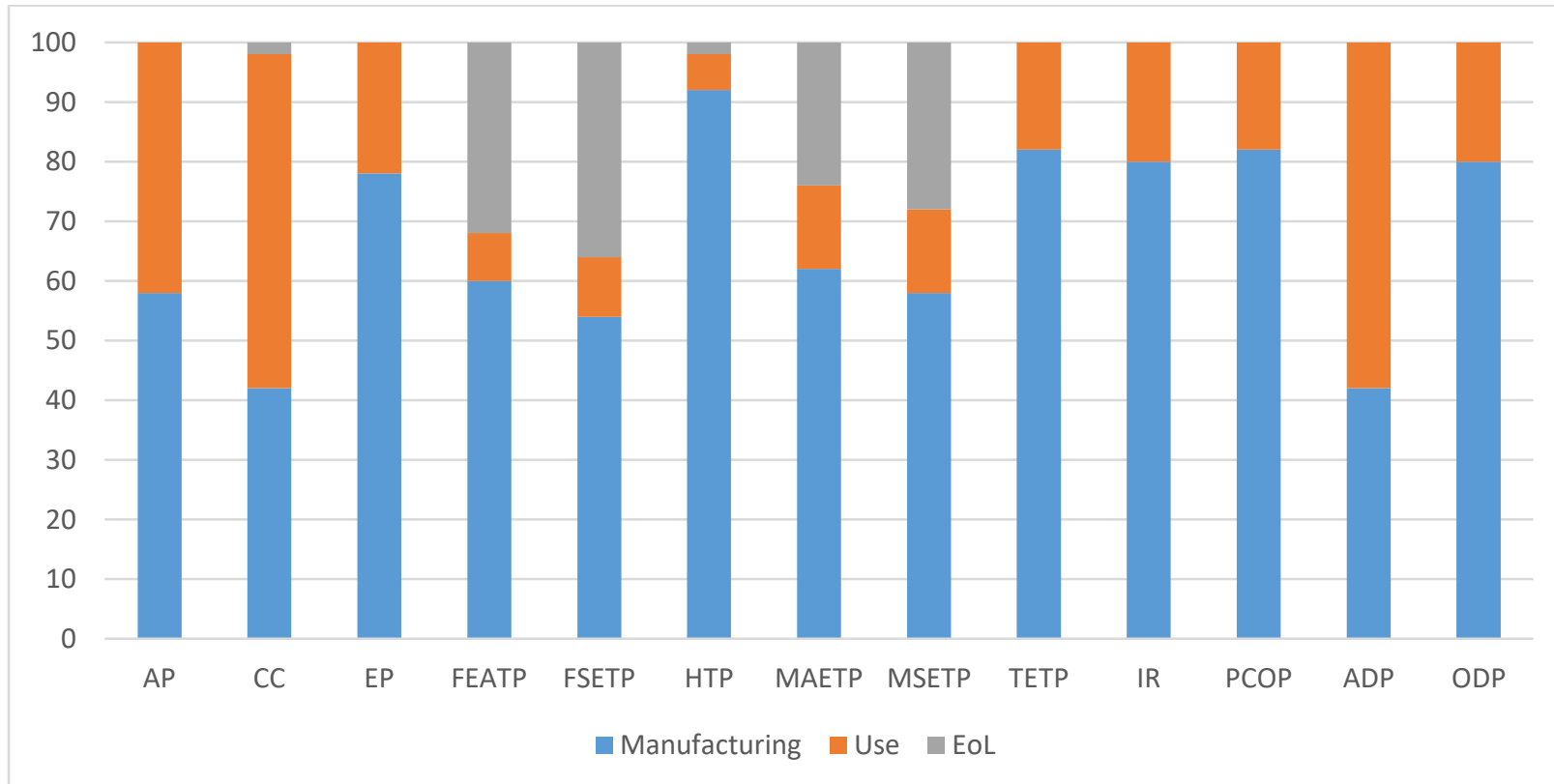

Figure 10. LCA results of LCD Cellphone across all the phases [22]

The manufacturing phase dominates in all the categories for all LCD cellphones as shown in Fig 10. The LCD of cellphones consume less power, so the effect of use phase is very low in most of the categories except acidification potential, climate change and abiotic depletion categories. It contributes negligibly to all ecotoxicity categories. The EoL phase effect significantly in term of FAETP, FSETP, MAETP, and MSETP and also to some extent in term of acidification potential and climate change, unlike LCD monitor and TV. 


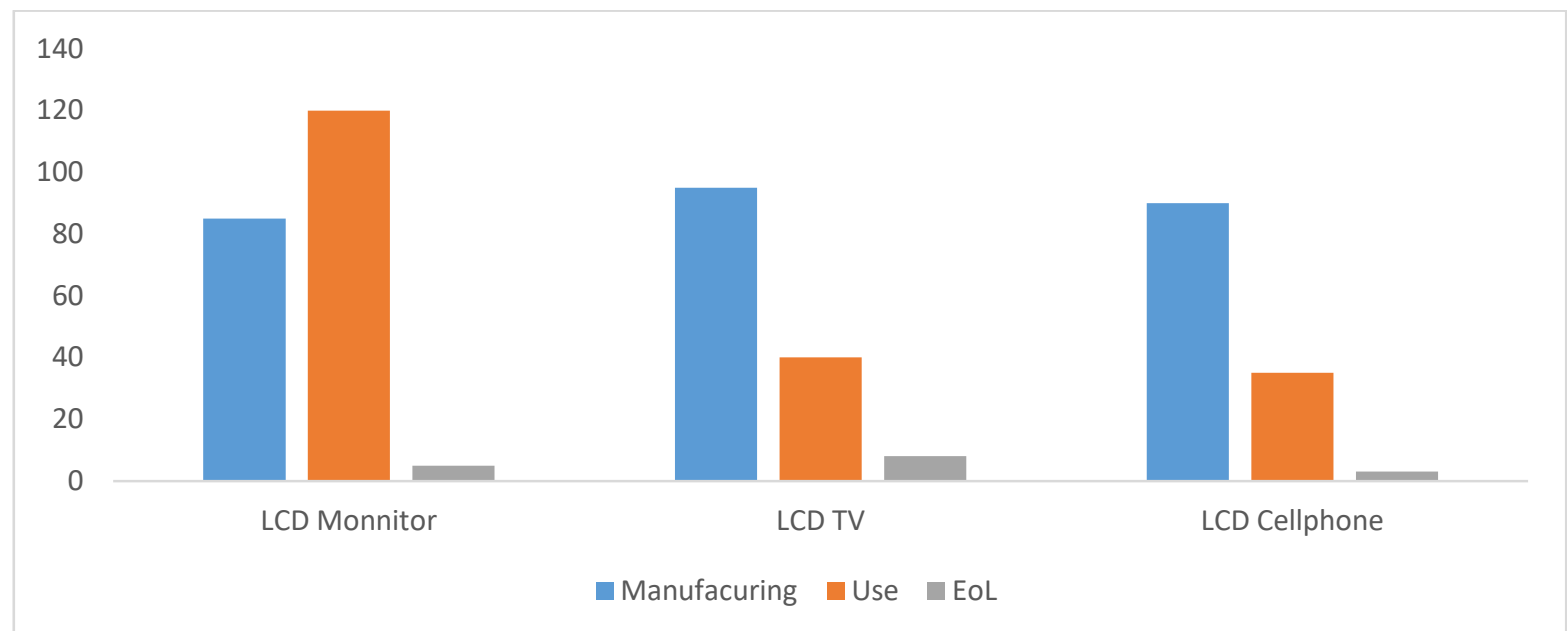

Figure 11. Climate change potential of LCD Monitor [22], LCD TV and LCD cellphone ( $\mathrm{Kg} \mathrm{CO} 2$ eq.)

Figure 11 shows that for LCD Monitor, use phase dominates for the emission. In LCD TV and LCD cellphones, manufacturing phase is major factor. EoL phase is very low in all the cases. In order to show the impact of changing materials in LCD products we used sustainable minds software. According to table 3 shows the breakdown of LCD components. As it indicates that steel (ferrous) is the dominating material with $33.5 \%$. In order to use this information, we need to know the weight of the screen in cell phones. From [19] shows that 40g is the weight of the screen in IPhone $6 \mathrm{~s}$, assuming that the LCD in monitors and TVs has the same components in LCD in cell phones. From that we calculated the weight of steel inside the LCD of IPhone $6 \mathrm{~s}$ which is equal to $13.4 \mathrm{~g}$. Using sustainable minds software, we conducted a study using only steel low alloy. The reference model is shown in figure 12 .

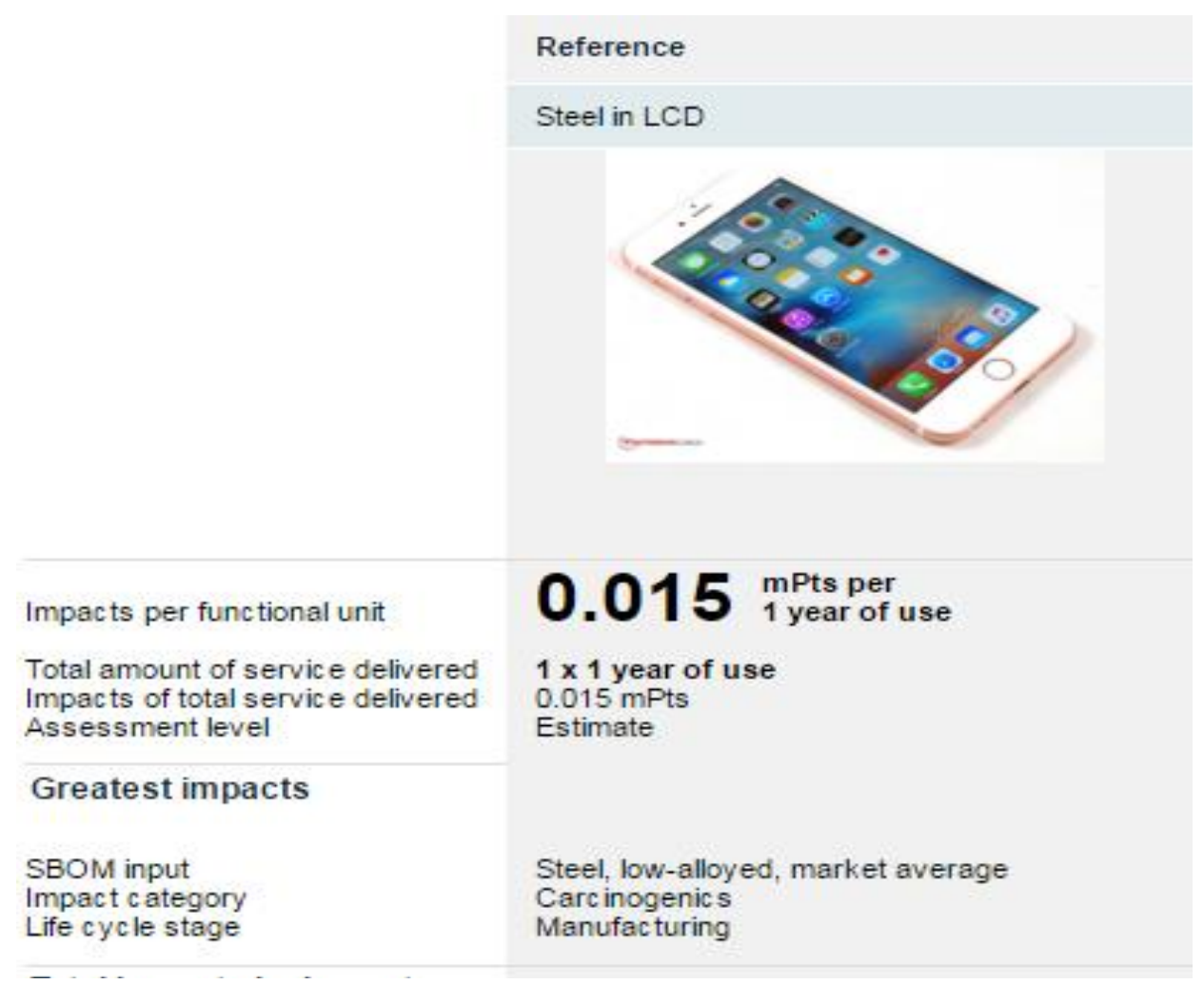

Figure 12. Reference concept for Cellphone model in Sustainable Mind

In the analysis we change the material to Steel, converter, low-alloyed, 25\% secondary, where it has low environmental impacts, as the below figure shows. 


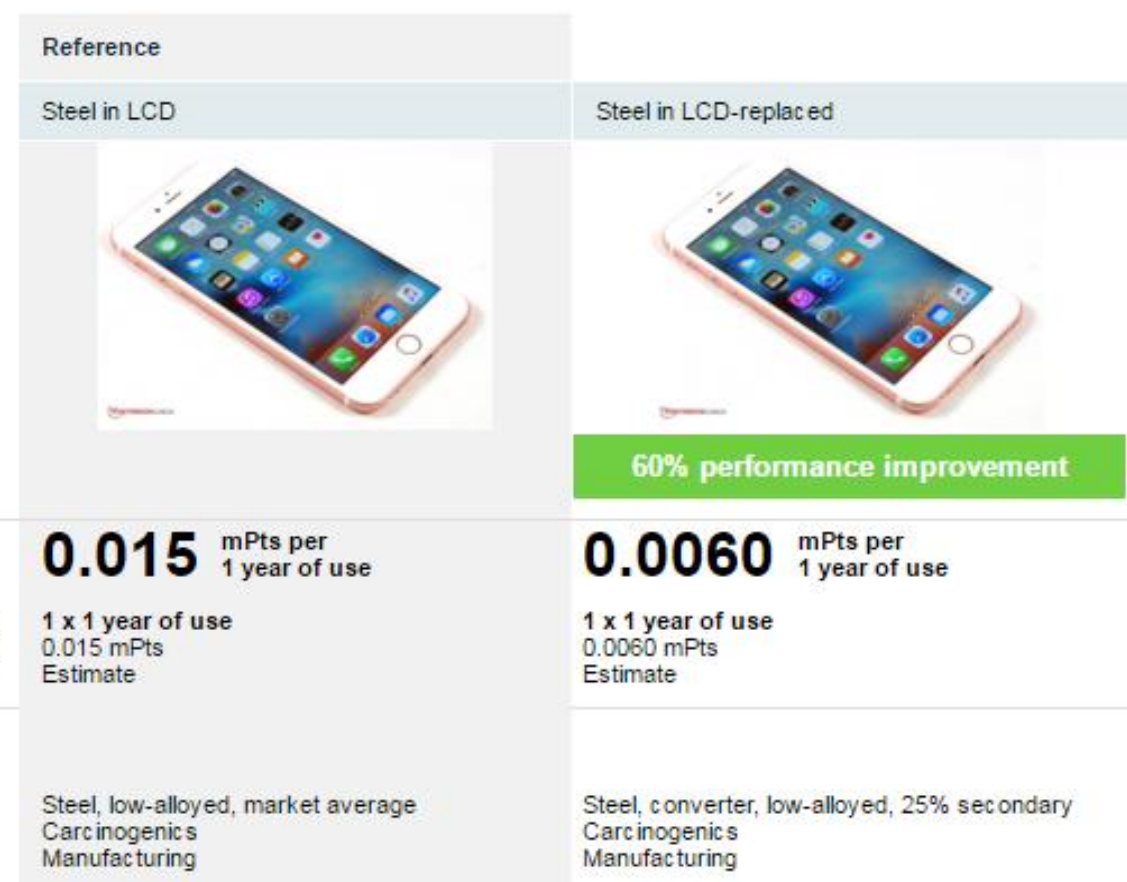

Figure 13. Optimized concept for Cellphone model in Sustainable Mind

In this study we only focused on the manufacturing stage, and this change provide very good improvement.

\subsubsection{Sensitivity Analysis}

To check the robustness of the results, a sensitivity analysis has been performed on the impact assessment data. A typical sensitivity analysis is performed by changing one of the input independent variable and at the same time measuring its influence on the dependent variable(s). It measures how different values of an independent variable will impact a particular dependent variable under different conditions. Sensitivity analysis is very useful for measuring the impact of two or more than two assumed independent variables. In this case US electricity mix was replaced with the Europe electricity mix [23] to measure robustness of the model as shown in table

Table 5. Europe [23] and US Electricity mix

\begin{tabular}{|l|l|l|}
\hline Energy Source & Europe Electricity Mix & US Electricity Mix \\
\hline Coal + Ignite & $43.24 \%$ & $67.9 \%$ \\
\hline Oil & $1.42 \%$ & $1.0 \%$ \\
\hline Natural Gas & $14.94 \%$ & $11.6 \%$ \\
\hline Nuclear Power & $23.76 \%$ & $2.3 \%$ \\
\hline Wind Power & $10.37 \%$ & $2.3 \%$ \\
\hline Biomass Power & $1.74 \%$ & $0.9 \%$ \\
\hline Hydroelectricity & $1.57 \%$ & $1.0 \%$ \\
\hline
\end{tabular}

Table 5 shows that the effect of change of electricity mixes during the lifecycle phases. It clearly indicates that with the change of electricity mix, the trends are similar across the life cycles of cellphones. The Europe and US electricity mixes are giving similar values for manufacturing and EoL phases where the electricity consumption is low.

\subsection{Economic Feasibility}

Composition of material, Market value and Recovery value for a LCD screen of cellphone was considered in dismantling case. For precise yields, a market research was assumed and costs and revenues of dismantling and recycling were calculated. Data of cellphone LCD is extracted from the data of LCD of Monitor. 
Table 6. Potential value streams of an LCD Cellphone [20]

\begin{tabular}{|l|l|l|l|}
\hline & Average Weight $\mathbf{( l b )}$ & Market Value (\$/lb) & Recovery Value (\$) \\
\hline Steel & 1.15 & 0.79 & 0.91 \\
\hline Mixed Plastics & 1.48 & 0.19 & 0.28 \\
\hline Wire and Cable & 0.02 & 0.93 & 0.02 \\
\hline Screen Driver Circuit & 0.08 & 6.56 & 0.53 \\
\hline Other Circuit Boards & 0.3 & 4.28 & 1.28 \\
\hline Backlight Lamps & $2-4$ pieces & $-\$ 0.40 /$ piece & -1.20 \\
\hline Recovery Value Total & \multicolumn{3}{|c|}{$\$ 1.82$} \\
\hline
\end{tabular}

After obtaining datasets for LCD monitors, LCD TV and LCD cellphones, the average material composition of all types of products is shown in Table 6. As potential valuable and marketable plastics PMMA from the film sets, ABS and PCABS (Polycarbonate - Acrylonitrile butadiene styrene) were identified in Table 7.

Table 7. Material revenues from dismantling output of LCD monitor, LCD TV and LCD cellphone [4]

\begin{tabular}{|l|l|l|l|l|l|l|l|}
\hline Material & $\begin{array}{l}\text { Composition } \\
\text { Monitor }\end{array}$ & $\begin{array}{l}\text { Composition } \\
\text { TV }\end{array}$ & $\begin{array}{l}\text { Composition } \\
\text { Phones }\end{array}$ & Revenue/cost & $\begin{array}{l}\text { Revenue } \\
\text { Monitor }\end{array}$ & $\begin{array}{l}\text { Revenue } \\
\text { TV }\end{array}$ & $\begin{array}{l}\text { Revenue } \\
\text { Phones }\end{array}$ \\
\hline $\begin{array}{l}\text { Ferrous } \\
\text { Metal }\end{array}$ & 409 & 535 & 259 & 0.04 & 16 & 21 & 10 \\
\hline Aluminum & 52 & 6 & 4 & 0.55 & 29 & 3 & 2 \\
\hline $\begin{array}{l}\text { Printed } \\
\text { circuit } \\
\text { boards }\end{array}$ & 81 & 61 & 43 & 2.00 & 163 & 122 & 86 \\
\hline Cables & 11 & 9 & 7 & 0.70 & 8 & 7 & 5 \\
\hline Backlight & 3 & 11 & 8 & -0.70 & -2 & -8 & -5 \\
\hline $\begin{array}{l}\text { LC } \\
\text { Display }\end{array}$ & 81 & 77 & 65 & -0.60 & -49 & -46 & -39 \\
\hline ABS & 120 & 179 & 115 & 0.13 & 16 & 23 & 15 \\
\hline PC-ABS & 43 & 0 & 15 & 0.13 & 6 & 0 & 2 \\
\hline PMMA & 124 & 17 & 55 & 0.15 & 19 & 2 & 8 \\
\hline PS & 5 & 43 & 37 & 0.05 & 0 & 2 & 2 \\
\hline $\begin{array}{l}\text { Other } \\
\text { plastics }\end{array}$ & 20 & 36 & 27 & -0.16 & -3 & -6 & -6 \\
\hline $\begin{array}{l}\text { Plastics } \\
\text { (FR) }\end{array}$ & 50 & 26 & 38 & -0.16 & -8 & -4 & -6 \\
\hline Total & 1000 & 1000 & 673 & & 194 & 117 & 74 \\
\hline
\end{tabular}

For the calculation of dismantling cost, an hourly rate of $18 \$$, incl. an overhead of $25 \%$ was used. This is a simplified approach that does not include the installation of a dismantling workplace and the storage of the appliances. Dismantling costs per ton of monitors, TV-sets and cellphones from the case study are shown in table 8

Table 8. Dismantling costs for Monitor, TV and Cellphones [4]

\begin{tabular}{|l|l|l|l|}
\hline & $\begin{array}{l}\text { Dismantling Time } \\
(\mathbf{m i n} / \mathbf{u n i t})\end{array}$ & $\begin{array}{l}\text { Average Weight } \\
(\mathbf{k g} / \mathbf{u n i t})\end{array}$ & $\begin{array}{l}\text { Dismantling Cost } \\
\mathbf{( \$ \mathbf { t } )}\end{array}$ \\
\hline Monitor & 18 & 5.7 & -948 \\
\hline TV & 24 & 15.1 & -477 \\
\hline Cell Phones & 20 & 0.2 & -128 \\
\hline
\end{tabular}

A balance of costs and revenues is given in table 9. For monitors, TV-sets and cellphones, costs of dismantling were considerably higher than material revenues. Labor costs were a main cost factor in the dismantling process. In the trials, specifically the removal of the fragile backlights took much time in the dismantling process. 
Table 9. Balance of costs and revenues for LCD monitors, TV-sets and Cellphones [4]

\begin{tabular}{|l|l|l|l|}
\hline & Monitor & TV & Cell Phones \\
\hline Material Revenues (\$/t) & 194 & 117 & 74 \\
\hline Dismantling Cost $\$$ /t) & -948 & -477 & -128 \\
\hline Total $(\$ /$ t) & -755 & -359 & -54 \\
\hline Total $(\$ /$ unit) & -4.30 & -5.43 & -1.92 \\
\hline
\end{tabular}

Costs and revenues shown here are valid for this trial. As material revenues can change considerably over time and labor costs may be different in other regions this can lead to a different balance.

\section{CONCLUSION}

In the initial stages of research into LCD recycling, the consensus was that the problem was focused towards the End-Of-Life of an LCD application. Our main focus was LCD's in phones as preliminary research suggested the exponential trend of LCD's being deemed out of service would pose a serious problem to the environment and raise potential hazards to wildlife and human health. Therefore, we aimed to focus our research in the betterment of LCD recycling. However, when conducting our trials, the improvement of LCD recycling only played a minimal role in the whole life cycle process.

In the Environmental Feasibility section of the results it was found that manufacturing, not the End-Of-Life of the product was the largest contributor of toxins, when preforming an entire life cycle analysis. In figure 10 of the results section, three different stages of the life of the phone, Manufacturing, Use, End-Of-Life. These three sections where then compared to 13 different areas that an LCD could pose a threat to, some of these being, including climate change, human toxicity potential and ozone depletion potential. Although shocked the results were absolutely stunning. Our research suggests something different than what another researcher suggested and that is that the area to be most concerned about, in regards to LCD products is the manufacturing side. The manufacturing side represented no less than $40 \%$ of the pollution in each category.

In order to be more confident in our findings we also looked at the economic feasibility of recycling these products and what was found was not promising. When focusing on LCD's in cellphones it was found that the recovery value of the phones at $\$ 74$ is drastically outweighed by the dismantling costs of around $\$ 128 /$ hour. This was definitely an area that was extremely defeating in the sense that in order to convince most people or companies to change the focus had to have a high recovery value in order to drive people to recycle LCD products. With that being said we turned to improving the manufacturing side.
By using the sustainable minds software, we ran tests that involved changing the steel in the phone which was the highest used material in phones at $33.5 \%$. By changing this steel from a steel, low-alloyed, market-average, what is used today, and replaced it with steel, converter, lowalloyed, 25\% secondary steel, the performance improvement was significantly improved by over $60 \%$. This drastic performance improvement showing promising results for continuing research in the way of LCD efficiency. These sort of improvements is what the focus of the research field should shift to as it is the area with the greatest amount of biological and ecological effects and as shown through our tests those performance numbers can be improved for the future.

In conducting this research, it was found to be extremely hard to obtain information in regards to LCD recycling and through research we now have more insight as to why that may be. In representing only, a small portion of the impacts to the environment and the negative return on products when recycling, we believe that researchers should shift their focus to the manufacturing side of LCD products. It is here where future researchers and companies can make tremendous improvements to improve this area through implementation of a more sustainable systems and more efficient products. In doing so, we hope to create more sustainable LCD products and reduce the impact it has on the environment.

\section{REFERENCES}

[1]. Elo, K. (2013). AUTOMATION IN THE RECYCLING INDUSTRY RECYCLING OF PLASTICS AND LARGE LIQUID CRYSTAL DISPLAYS. Sweden: Division for Manufacturing Engineering Department for Management and Engineering Linköping University.

[2]. O’Donoghue, L., Leen, J., Ryan, A., \& Ruiz, J. (2007-2013). State-of-the-Art Recycling Technology for Liquid. Ireland: Environmental Protection Agency.

[3]. Ryan, A., Donoghue, L. O., \& Lewis, H. (June-July 2011). Characterizing components of liquid crystal displays to facilitate disassembly. Journal of Cleaner Production. Retrieved from

[4]. Salhofer, S., Spitzbart, M., \& Maurer, K. (2011). Recycling of LCD Screens in 
Europe - State of the Art and Challenges. In J. Hesselbach, \& C. Herrmann, Glocalized Solutions for Sustainability in Manufacturing: Proceedings of the 18th CIRP International Conference on Life Cycle Engineering (pp. 454-458). Braunschweig, Germany: Technische Universität Braunschweig. doi:10.1007/9783-642-19692-8_78

[5]. TECHNICAL MEMORANDUM: End-ofLife Approach for the DfE Computer Display Project. (December 2001). In N. S. (NSCEP), Desktop Computer Displays: Life-Cycle Assessment (p. APPENDIX I). United States Environmental Protection Agency.

[6]. Zhuang, X., He, W., Li, G., Huang, J., \& Ye, Y. (2012). Materials separation from waste liquid crystal displays using combined physical methods. Polish Journal of Environmental Studies, 21(6), 1921-1927.

[7]. Tyagi, A., \& Chatterjee, S. Liquid Crystal Display: Environment \& Technology.

[8]. Venere, Emil. "New Tools to Aid in Recycling Flat-screen Monitors, TVs." Purdue University. Purdue University, 9 Oct. 2009. Web. 24 Feb. 2016.

[9]. Silveria, A., Fuchs, M., Pinheiro, D., Tanabe, E., \& Bertuol, D. (8 april 2015). Recovery of indium from LCD screens of discarded cell phones.Waste Management, 1-9. Retrieved February 22, 2016.

[10]. Underwriters Laboratories Inc., 2011, A UL white paper "The Life Cycle of Materials in Mobile Phones"

[11]. Silveira, G. T., \& Chang, S. (2010). Cell phone recycling experiences in the United States and potential recycling options in Brazil. Waste Management, 30(11), 22782291.

[12]. Vanegas, P., Peeters, J. R., Dewulf, W., Cattrysse, D., \& Duflou, J. R. (2015). Improving Resource Efficiency through Recycling Modelling: A Case Study for LCD TVs. Procedia CIRP, 26, 601-606.

[13]. BUZATU, M., \& MILEA, N. B. (n.d.). RECYCLING THE LIQUID CRYSTAL DISPLAYS. U.P.B. Sci. Bull, 70(4), 2008th ser., 95-102.

[14]. Geyer, R., \& Blass, V. D. (2009). The economics of cell phone reuse and recycling. The International Journal of Advanced Manufacturing Technology Int J Adv Manuf Technol, 47(5-8), 515-525.

[15]. Soo, V. K., \& Doolan, M. (2014). Recycling Mobile Phone Impact on Life Cycle Assessment. Procedia CIRP, 15, 263-271.
[16]. Venere, Emil. "New Tools to Aid in Recycling Flat-screen Monitors, TVs." Purdue University. Purdue University, 9 Oct. 2009. Web. 24 Feb. 2016.

[17]. Takahashi, K. I., Tsuda, M., Nakamura, J., Otabe, K., Tsuruoka, M., Matsuno, Y., \& Adachi, Y. (2009). Elementary analysis of mobile phones for optimizing end-of-life scenarios. 2009 IEEE International Symposium on Sustainable Systems and Technology.

[18]. Facts and Figures on E-Waste and Recycling. (n.d.). Retrieved from http://www.electronicstakeback.com/wpcont ent/uploads/Facts_and_Figures_on_EWaste_ and_Recycling.pdf

[19]. Gardiner, M. (2015, September 15). IPhone 6s Specs: New iPhone Will Be Heavier Than Your iPhone 4. Retrieved April 06, 2016, from http://www.idigitaltimes.com/iphone6s-specs-new-iphone-will-be-heavier-youriphone-4-475155

[20]. http://www.istc.illinois.edu/about/seminarpr esentations/20130905.pdf

[21]. Zhang, K., Wu, Y., Wang, W., Li, B., Zhang, Y., \& Zuo, T. (2015). Review: Recycling indium from waste LCDs: A review. Resources, Conservation \& Recycling, 104(Part A), 276-290. doi:10.1016/j.resconrec.2015.07.015

[22]. Bhakar, V., Agur, A., Digalwar, A., \& Sangwan, K. S. (2015). Life Cycle Assessment of CRT, LCD and LED Monitors. Procedia CIRP,29(The 22nd CIRP Conference on Life Cycle Engineering), 432-437. doi:10.1016/j.procir.2015.02.003

[23]. Annual Report 2009-2010. Central Electricity Authority, Ministry of Power; www.cea.nic.in/sitemap.html, accessed on June 15, 2011.

[24]. Lee, S., Noon, M., \& Cooper, J. S. (2011). Toward the Estimation of Liquid Crystal Display Materials for Waste Management and Other Assessments. IEEE Transactions On Components, Packaging \& Manufacturing Technology, 1(6), 934-950. 